\title{
Synthesis of FAU zeolite from aluminoborosilicate glass and elution behavior of glass components
}

\author{
Masato TSUJIGUCHI, ${ }^{\dagger}$ Tadashi KOBASHI, Yasuhiko UTSUMI, \\ Nobuaki KAKIMORI and Atsushi NAKAHIRA* \\ Environmental Research and Development Center, Sharp Corporation, 1 Takumi-cho, Sakai-ku, Sakai 590-8522, Japan \\ *Department of Material Science, Osaka Prefecture University, Sakai 599-8531, Japan
}

\begin{abstract}
We tried to synthesize FAU zeolite from alumonoborosilicate glass used in liquid crystal displays, of which the discard volume is supposed to increase in the near future. The effect of hydrothermal process factor on the synthesis of FAU zeolite using aluminoborosilicate glass, which is poorly alkaline-soluble, was investigated. From $X$-ray diffraction, with increasing aging time before hydrothermal treatment, the production of FAU zeolite increased, whereas, that of zeolite $P$ decreased. From inductively coupled plasma atomic emission spectrometry, the concentration of $\mathrm{Si}$ in the solution increased and that of Al decreased during aging. This indicates that aluminosilicate was generated from Si from aluminoborosilicate glass and Al from sodium aluminate. With aging time, generated aluminosilicate was aged, resulting in preferential synthesis of FAU zeolite. From scanning electron microscopy, increasing aging time resulted in a small crystal particle size of the synthesized FAU zeolite. At higher aging temperature than room temperature, the dissolution of aluminoborosilicate glass was accelerated, zeolite $P$ increased. When $\mathrm{NaOH}$ concentration of aqueous solution decreased, zeolite $\mathrm{A}$ was synthesized. This indicates that aluminoborosilicate glass did not elute substantially, therefore low silica zeolite was generated. At higher $\mathrm{NaOH}$ concentration, FAU zeolite was generated because $\mathrm{Na}^{+}$ion stabilized FAU zeolite and more $\mathrm{Si}$ eluted from aluminoborosilicate glass. Zeolite $\mathrm{P}$ which is a stable phase was generated when hydrothermal treatment temperature was high and treatment time became long. From nitrogen adsorption/ desorption measurements, the microstructure of the obtained product was almost the same as the pure FAU zeolite. We clarified the potential of aluminoborosilicate glass as a starting material of FAU zeolite, widely used in catalysts, adsorbents, gas separation agents and so on.
\end{abstract}

(C2014 The Ceramic Society of Japan. All rights reserved.

Key-words : FAU zeolite, Aluminoborosilicate glass, Synthesis, Aging, Hydrothermal treatment

[Received September 11, 2013; Accepted November 5, 2013]

\section{Introduction}

LCD panels are widely used in televisions, personal computers, smartphones, tablets, digital cameras and so on. In 2011, global TV demand was about 2000 million, more than half of which was for LCD TVs. ${ }^{1)}$

Recently, people have become more concerned about environmental problems, therefore it is necessary to make efficient use of materials from discarded LCD TVs, given that the discard volume of LCD TVs is going to increase in the near future. The main component of an LCD panel is a glass substrate, therefore the recycling of the aluminoborosilicate glass used in the glass substrate is an important issue.

By the way, zeolites are microporous aluminosilicate materials with a uniform pore size of less than $2 \mathrm{~nm}$ and chemically, mechanically, and thermally stable. ${ }^{2)}$ Zeolites are applied as catalysts, adsorbents, gas separation membranes, detergent builders and so on because of their excellent adsorptive capacity, gas separation property and ion-exchange capacity, which owes to the unique microporous structure.

Generally, zeolites are synthesized from a silica source, an alumina source, a mineralizer (alkali metal hydroxide) and water. ${ }^{2)}$ There are many previous studies on the synthesis process of zeolite A and FAU-type zeolite, which are widely used for indus-

Corresponding author: M. Tsujiguchi; E-mail: tsujiguchi.masato@ sharp.co.jp trial purposes. ${ }^{2-11)}$ Zeolites with an FAU-type framework are classified into zeolite $\mathrm{X}$ and zeolite $\mathrm{Y}$ according to the Si/Al molar ratio. ${ }^{12), 13)}$ The synthesis of FAU zeolite attracts much attention because of its wide industrial use, such as a fluid catalytic cracking catalyst that utilizes the solid acid properties of zeolite $\mathrm{Y}^{14)-17)}$ and a gas separation agent that utilizes the adsorptive performance of zeolite $\mathrm{X}^{18)}$ Accordingly, many studies of the synthesis of FAU zeolite have been carried out. As for the synthesis of FAU zeolite, many studies have been focused on suppressing the development of phases other than FAU. ${ }^{3)-7)}$ Generally, it is synthesized by hydrothermal treatment after aging aluminosilicate gel generated from the starting material for a few hours. ${ }^{3)-5)}$ Colloidal silica is one of the preferred sources of silica for obtaining zeolite Y. In the previous research into the synthesis of zeolite from blast furnace slag using a starting material that was pre-treated to have an $\mathrm{SiO}_{2}$ content of $90 \%$, highly-pure FAU zeolite was synthesized by hydrothermal treatment. ${ }^{8)-10)}$ Starting materials that contains highpure $\mathrm{SiO}_{2}$, such as colloidal silica and pre-treated blast furnace slag, readily elute alkaline solution during hydrothermal treatment, whereby generating homogeneous Si solution. Therefore, FAU zeolite could be synthesize by brief hydrothermal treatment.

Aluminoborosilicate glass mainly consists of $\mathrm{SiO}_{2}, \mathrm{Al}_{2} \mathrm{O}_{3}$, $\mathrm{B}_{2} \mathrm{O}_{3}$ and alkaline earth oxides, and is probably suitable for zeolite ingredient because $\mathrm{SiO}_{2}$ and $\mathrm{Al}_{2} \mathrm{O}_{3}$ are the main components. We can also make effective use of aluminoborosilicate glass as a mechanically-excellent and transparent substrate or base material such as large particles or plates. Furthermore, hydro- 
thermal treatment which is a typical method to synthesize zeolites is at low temperature relative to fusing process. The high softening temperature of aluminoborosilicate glass is not a problem for hydrothermal treatment. In a previous paper about the synthesis of zeolites from aluminoborosilicate glass, ${ }^{19)}$ relatively high silica and stable zeolite such as GIS zeolite (zeolite P) and ANA zeolite were obtained by hydrothermal treatment.

We tried to synthesize FAU zeolite to increase the potential of aluminoborosilicate glass as a starting material of zeolite. Aluminoborosilicate glass has chemical resistance and is less soluble in alkaline solution than colloidal silica. The generation of aluminosilicate species, which occurs in alkaline solution, is difficult with aluminoborosilicate glass. Therefore, it was predicted that FAU zeolite nucleation would be difficult to promote. Moreover, the glass components, which are not original framework components of zeolites, such as alkaline earth oxide, may block the generation of zeolites.

In this study, the synthesis of FAU zeolite from aluminoborosilicate glass was tried. The microstructure of the product was also investigated. We focused on the relationship between the elution behavior of aluminoborosilicate glass and FAU zeolite synthesis, because aluminoborosilicate glass is barely soluble in alkaline solution and FAU zeolite is susceptible to the solution composition. The effect of the composition, aging process and hydrothermal condition were investigated. And, we discuss the relationship between the elution of glass and zeolite synthesis.

\section{Experimental}

\subsection{Glass sample preparation}

In this study, a commercial aluminoborosilicate glass was used as a starting material. Glass sample was treated with ball milling for a few hours until the particle size was approximately $8 \mu \mathrm{m}$ in median particle diameter.

The composition of aluminoborosilicate glass was $\mathrm{SiO}_{2}: 63$, $\mathrm{Al}_{2} \mathrm{O}_{3}: 18, \mathrm{~B}_{2} \mathrm{O}_{3}: 10, \mathrm{CaO}: 8, \mathrm{MgO}: 1 \mathrm{wt} \% .{ }^{19)}$ Aluminoborosilicate glass had silica and aluminum as its main components. Therefore, it is suitable for a starting material of zeolites, which are crystalline aluminosilicates.

By acid treatment, we tried to remove components of the glass that were not the original components of the zeolites, as carried out in the synthesis of zeolite from blast furnace slag. ${ }^{11)}$ The acidtreated glass was obtained as follows. $10 \mathrm{~g}$ of the glass powder sample was mixed with $250 \mathrm{~mL} 5 \mathrm{~mol} / \mathrm{L}$ nitric acid solution $\left(\mathrm{HNO}_{3}\right.$; Wako Pure Chemical Industries Ltd., Japan), then stirred at $348 \mathrm{~K}$ for $3 \mathrm{~h}$. After that, it was filtered, washed and dried at $323 \mathrm{~K}$ for $24 \mathrm{~h}$. From inductively coupled plasma atomic emission spectrometry (ICP-AES, ICPE-9000, Shimadzu, Japan) of the acid solution, the dissolution rates of $\mathrm{B}_{2} \mathrm{O}_{3}, \mathrm{CaO}$ and $\mathrm{MgO}$ were 7,5 and $4 \mathrm{wt} \%$, respectively. $\mathrm{SiO}_{2}$ has seldom eluted into the acid solution.

\subsection{Effect of Si/Al ratio and $\mathrm{NaOH}$ concentration on the synthesis of FAU zeolite}

First, the effect of the mixing ratio of starting materials, which determine $\mathrm{Si} / \mathrm{Al}$ ratio, was investigated. Sodium aluminate $\left(\mathrm{NaAlO}_{2}\right.$; Kanto Chemical Co., Inc., Japan) of $0.25,0.17$ and $0.10 \mathrm{~g}$ were added to $0.91 \mathrm{~g}$ of glass powder sample to create $\mathrm{Si} /$ $\mathrm{Al}=1.9,2.1$ and 2.3. And, $14 \mathrm{~mL}$ of sodium hydroxide $(\mathrm{NaOH})$ aqueous solution with a concentration of $2.0 \mathrm{~mol} / \mathrm{L}$ was prepared by adding $1.1 \mathrm{~g}$ of $\mathrm{NaOH}$ (Wako Pure Chemical Industries Ltd., Japan) to $14 \mathrm{~mL}$ of deionized water. The mixture of sodium aluminate and $\mathrm{NaOH}$ aqueous solution was set into Teflon vessel of $28 \mathrm{~mL}$, then stirred for $0.16 \mathrm{~h}$ and aged at room temperature for
$96 \mathrm{~h}$ without stirring. Then, they were hydrothermally treated at $348 \mathrm{~K}$ for $96 \mathrm{~h}$. After hydrothermal treatment, the products were filtered, washed and then dried in an oven at $323 \mathrm{~K}$ for $24 \mathrm{~h}$.

The effect of the concentration of $\mathrm{NaOH}$ aqueous solution was also investigated. 1.0, 2.0 and $3.0 \mathrm{~mol} / \mathrm{L} \mathrm{NaOH}$ aqueous solutions were prepared. $0.91 \mathrm{~g}$ of glass powder sample and $0.17 \mathrm{~g}$ of $\mathrm{NaAlO}_{2}$ were mixed with $\mathrm{NaOH}$ aqueous solutions to create $\mathrm{Si} / \mathrm{Al}=2.1$. Then, the solutions were aged for $96 \mathrm{~h}$ and hydrothermally treated at $348 \mathrm{~K}$ for $96 \mathrm{~h}$.

\subsection{Effect of aging time and aging temperature on the synthesis of FAU zeolite}

The effect of aging was investigated. A mixture of glass and sodium aluminate with an $\mathrm{Si} / \mathrm{Al}$ ratio of 2.1, and $\mathrm{NaOH}$ aqueous solution with a concentration of $2.0 \mathrm{~mol} / \mathrm{L}$ were prepared. The samples were aged for $0,24,48,96,144,196$ and $240 \mathrm{~h}$, followed by hydrothermal treatment at $348 \mathrm{~K}$ for $96 \mathrm{~h}$. To investigate the relationship between the elution of glass during aging and zeolite synthesis, compositions of solutions after aging were evaluated by ICP-AES.

The effect of aging temperature was also investigated. A mixture of glass and sodium aluminate with an $\mathrm{Si} / \mathrm{Al}$ ratio of 2.1, and $\mathrm{NaOH}$ aqueous solution with a concentration of $2.0 \mathrm{~mol} / \mathrm{L}$ were prepared. The samples were aged for $96 \mathrm{~h}$ at 298,313 and $323 \mathrm{~K}$ followed by hydrothermal treatment at $348 \mathrm{~K}$ for $96 \mathrm{~h}$.

\subsection{Effect of hydrothermal treatment conditions on the synthesis of FAU zeolite}

The effects of hydrothermal treatment conditions were investigated in the case of an $\mathrm{Si} / \mathrm{Al}$ ratio of $2.1, \mathrm{NaOH}$ concentration of $2.0 \mathrm{~mol} / \mathrm{L}$ and aging time of $96 \mathrm{~h}$ at $298 \mathrm{~K}$. Synthesis temperatures were $338,348,358$ and $368 \mathrm{~K}$, while synthesis time was $48,96,144$, and $192 \mathrm{~h}$.

\subsection{Characterization of products}

The products obtained by hydrothermal treatment were identified by powder X-ray diffractometry (XRD, Mini Flex II, Rigaku, Japan) with $\mathrm{Cu} \mathrm{K} \alpha$ radiation, operating at $30 \mathrm{kV}$ and $15 \mathrm{~mA}$. The XRD of the commercial FAU zeolite (HS-320, Wako Pure Chemical Industries Ltd., Japan) was measured as a standard material. The micromorphologies of the products were observed by field emission scanning electron microscopy (FE-SEM, JSM$7401 \mathrm{~F}$, JEOL, Japan) at an acceleration voltage of $5 \mathrm{kV}$.

Ratios of produced zeolite phases were evaluated by reference intensity ratio (RIR) method, ${ }^{20)}$ in which diffracted X-ray intensity ratio was compared to a standard $\alpha$-alumina.

The crystallinities of zeolites were determined from the X-ray intensity ratio of the product to a standard at given diffraction faces as follows: zeolite A (200), hydroxysodalite (110), zeolite $\mathrm{P}(301) .{ }^{17)}$

Nitrogen adsorption isotherms at $77 \mathrm{~K}$ were obtained by an automatic gas adsorption measure apparatus (BELSORP-miniII, BEL Japan, Inc., Japan). The samples were pretreated at $473 \mathrm{~K}$ for $12 \mathrm{~h}$. The specific surface area of the samples was calculated by the BET(Brunauer-Emmet-Teller) method using adsorption data from $\mathrm{P} / \mathrm{P}_{0}=10^{-3}$ to $10^{-2}$.

\section{Results and discussion}

\subsection{Effect of $\mathrm{Si} / \mathrm{Al}$ ratio and $\mathrm{NaOH}$ concentration on the synthesis of FAU zeolite}

XRD patterns of products obtained from the mixture of glass and sodium aluminate with $\mathrm{Si} / \mathrm{Al}=1.9,2.1$ and 2.3 are summarized in Fig. 1. In the case of $\mathrm{Si} / \mathrm{Al}=1.9$, zeolite $\mathrm{A}$, which is 


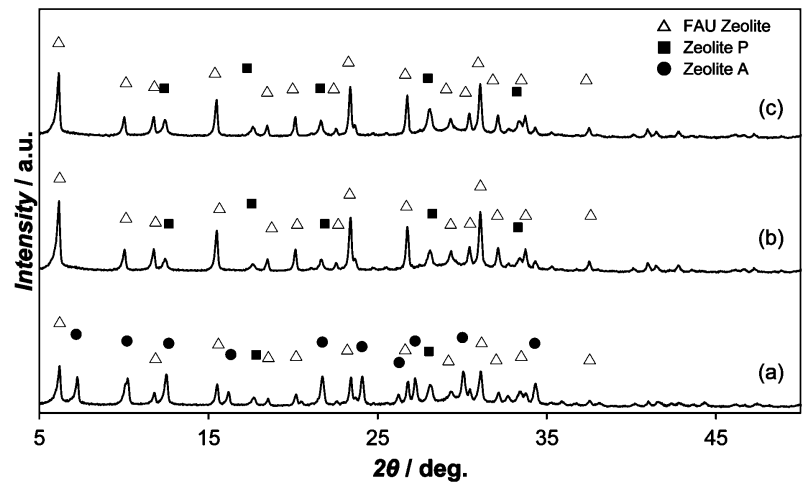

Fig. 1. XRD patterns of the products obtained by hydrothermal treatment at $348 \mathrm{~K}$ for $96 \mathrm{~h}$, after $96 \mathrm{~h}$ aging, with $2.0 \mathrm{~mol} / \mathrm{L} \mathrm{NaOH}$, when $\mathrm{Si} / \mathrm{Al}$ ratio was (a)1.9, (b)2.1 and (c)2.3.

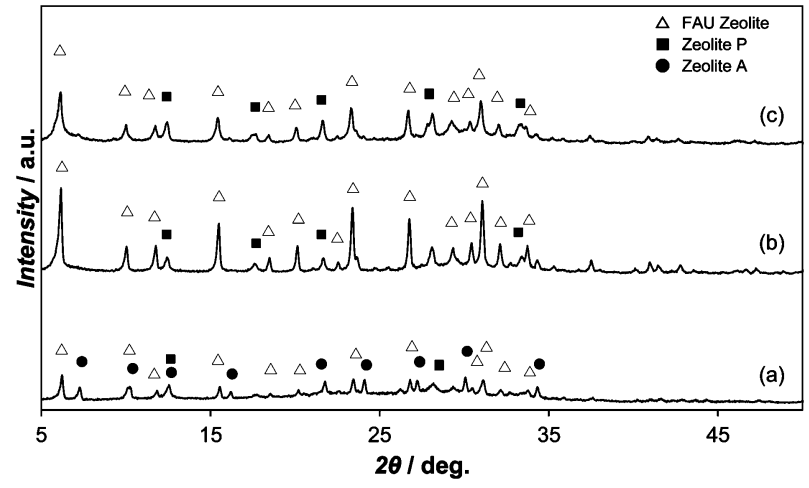

Fig. 2. XRD patterns of the products obtained by hydrothermal treatment at $348 \mathrm{~K}$ for $96 \mathrm{~h}$, after $96 \mathrm{~h}$ aging, with (a)1.0, (b)2.0 and (c) $3.0 \mathrm{~mol} / \mathrm{L} \mathrm{NaOH}$, when $\mathrm{Si} / \mathrm{Al}$ ratio was 2.1 .

low silica zeolite, was generated. In the case of $\mathrm{Si} / \mathrm{Al}=2.1$ and 2.3, FAU zeolite and zeolite $\mathrm{P}$ were generated simultaneously. Zeolite $\mathrm{P}$ is relatively high silica zeolite and easily generated from waste materials such as coal fly ash and blast furnace slag. ${ }^{21)}$ From X-ray diffractions, the production volume of FAU was highest in $\mathrm{Si} / \mathrm{Al}=2.1$.

The effect of $\mathrm{NaOH}$ concentration of the solution on the synthesis of FAU zeolite was investigated. Figure 2 shows XRD patterns of the products using 1,2 and $3 \mathrm{~mol} / \mathrm{L} \mathrm{NaOH}$ aqueous solutions. In $1 \mathrm{~mol} / \mathrm{L} \mathrm{NaOH}$, zeolite $\mathrm{A}$ and FAU zeolite were synthesized, whereas in 2 and $3 \mathrm{M} \mathrm{NaOH}$, FAU zeolite and zeolite $\mathrm{P}$ were generated. Aluminoborosilicate glass did not elute sufficiently in lower $\mathrm{NaOH}$ concentration, therefore the Si concentration in the solution was low and resultantly zeolite A, which is low silica zeolite, was generated. In higher $\mathrm{NaOH}$ concentrations, Si eluted well from glass and $\mathrm{Na}^{+}$ion had the effect of stabilizing FAU zeolite; as a result, FAU zeolite was generated. On the other hand, zeolite $\mathrm{P}$, which is a more stable phase, was also generated. In $3 \mathrm{~mol} / \mathrm{L} \mathrm{NaOH}$, the production of zeolite $\mathrm{P}$ increased relative to $2 \mathrm{~mol} / \mathrm{L} \mathrm{NaOH}$.

\subsection{Effect of aging time and aging temperature on the synthesis of FAU zeolite}

Figures 3(a) to 3(c) shows XRD patterns of the products obtained after aging for (a)48, (b) 96 , (c) $240 \mathrm{~h}$. Figure 4(d) shows the XRD pattern of the commercial FAU zeolite. From XRD patterns, FAU zeolite is dominant phase of the product with $240 \mathrm{~h}$

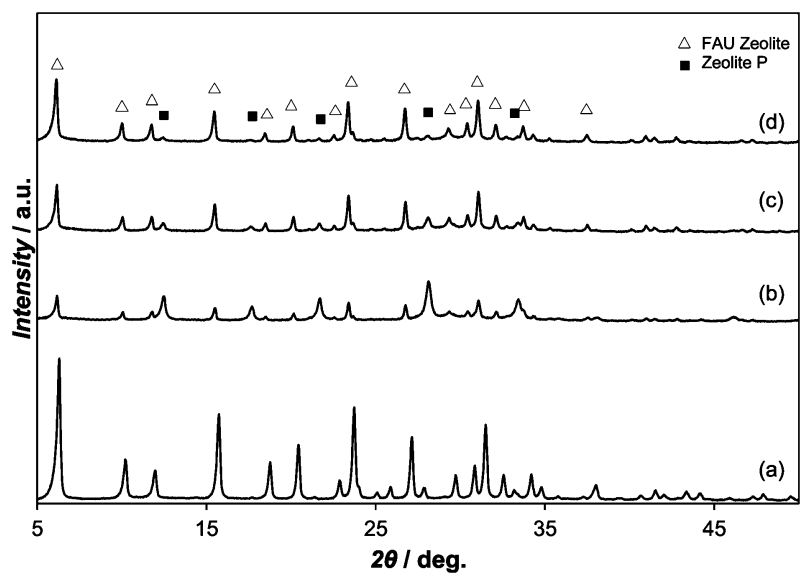

Fig. 3. XRD patterns of (a)the commercial FAU zeolite and the products obtained by hydrothermal treatment at $348 \mathrm{~K}$ for $96 \mathrm{~h}$, after (b) 48 , (c) 96 and (d) $240 \mathrm{~h}$ aging, with $2.0 \mathrm{~mol} / \mathrm{L} \mathrm{NaOH}$, when Si/Al ratio was 2.1 .

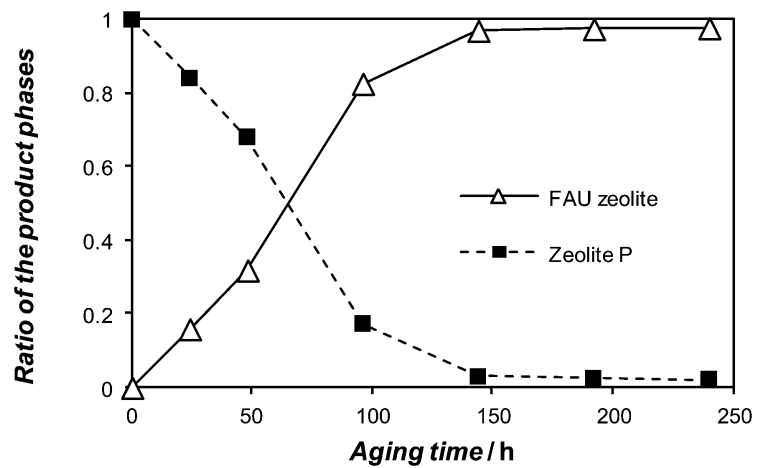

Fig. 4. Ratio of the product phases as a function of aging time when hydrothermally treated at $348 \mathrm{~K}$ for $96 \mathrm{~h}$ with $2.0 \mathrm{~mol} / \mathrm{L} \mathrm{NaOH}$. Si/Al ratio was 2.1 .

aging. From Fig. 3, the crystallinity of FAU zeolite obtained with aging time of $0 \mathrm{~h}$ was almost $0 \%$. Those of aging time of 48 and $96 \mathrm{~h}$ was about $14 \%$ and $43 \%$, respectively. This indicated that about half of glass phase was remained unreacted with long period of aging. Almost all of zeolite phases transformed into FAU zeolite in the case of $240 \mathrm{~h}$ aging.

In the synthesis of FAU zeolite, aging the solution is effective towards suppressing the development of other phases such as zeolite P. ${ }^{3)}$ Figure 4 shows the ratio of each crystalline zeolite phase produced by hydrothermal treatment as a function of aging time. Figure 4 was evaluated without consideration of non-crystalline phase, which was unreacted glass. In the previous report on the synthesis of FAU zeolite from colloidal silica, the production of FAU zeolite increased up to $12 \mathrm{~h}$ of aging. ${ }^{4)}$ However, in this study, the quantity of produced FAU zeolite was not so high after aging for $24 \mathrm{~h}$, but it gradually increased up to aging for $96 \mathrm{~h}$. And, it also increased from 96 to $240 \mathrm{~h}$ slightly, as shown in Fig. 4.

Figure 5 shows the concentrations of $\mathrm{Si}$ and $\mathrm{Al}$ in the solution after aging as a function of aging time. Si concentration in the solution, which was supplied from aluminoborosilicate glass, was almost $0 \mathrm{~mol} / \mathrm{L}$ just after mixing the starting materials, and it increased with aging time. Initially, Al was abundant in the solution because $\mathrm{NaAlO}_{2}$, which is water-soluble, was added as a starting material. But, $\mathrm{Al}$ concentration in the solution decreased 


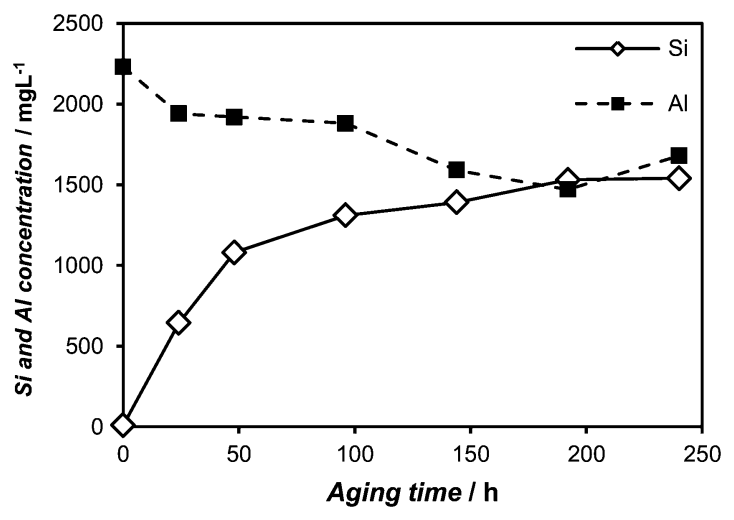

Fig. 5. Si and Al concentrations in the solution after aging as a function of aging time with $2.0 \mathrm{~mol} / \mathrm{L} \mathrm{NaOH}$. Si/Al ratio was 2.1 .

with aging time. These results indicate that $\mathrm{Si}$ eluted from aluminoborosilicate glass and $\mathrm{Al}$ dissolved in the solution generated insoluble aluminosilicate gel, and, as a result, Al concentration in the solution decreased. The solid phases aged for 0 to $240 \mathrm{~h}$ were non-crystalline, which means no crystalline phases were obtained. This indicates that insoluble aluminosilicate was of non-crystalline phase. According to the previous study on the synthesis of FAU zeolite from pure reagent, ${ }^{3)}$ by aging the solution for long hours, $\mathrm{Si}$ and $\mathrm{Al}$ reacted to generate aluminosilicate gel. The production of aluminosilicate gel increased with aging time and it causes preferential growth of FAU zeolite. In the synthesis of FAU zeolite from aluminoborosilicate glass, because aluminoborosilicate glass was hardly soluble, Si eluted into the alkaline aqueous solution very slightly during aging. And, it reacted with $\mathrm{Al}$ dissolved in the solution previously, to generate aluminosilicate gel. As a result, the production of FAU zeolite increased in the following hydrothermal treatment.

Figures 6(a) to 6(c) show SEM images of the products obtained after aging for 48,96 and $240 \mathrm{~h}$, followed by hydrothermal treatment at $348 \mathrm{~K}$ for $96 \mathrm{~h}$. The crystals of the products appeared as octahedral-like crystals, which are typical in FAU zeolite. ${ }^{3)}$ Crystalline particles of FAU zeolite became smaller with aging time, which is consistent with previous reports. The synthesized FAU zeolite crystal was 5 to $6 \mu \mathrm{m}$ in size in the case of $96 \mathrm{~h}$ aging, and 2 to $3 \mu \mathrm{m}$ in the case of $240 \mathrm{~h}$ aging. These results indicate that the size of crystal particle became smaller with aging time, as reported in the previous studies. ${ }^{3), 22)}$

Figure 7 shows XRD patterns of the products obtained after aging for $96 \mathrm{~h}$ at 398,413 and $423 \mathrm{~K}$. When the aging temperature rose with the same hydrothermal treatment, the production volume of zeolite $\mathrm{P}$ increased. This result indicated that the dissolution amount of $\mathrm{Si}$ increased substantially during aging at higher temperature, therefore the solution became Si-rich. This possibly resulted in alternation in the kind of the predominant zeolite phase.

\subsection{Effect of hydrothermal treatment conditions on the synthesis of FAU zeolite}

Then, we investigated the effect of the time of the hydrothermal treatment at $348 \mathrm{~K}$. Figure 8 shows the ratio of each produced zeolite phase as a function of synthesis time. Figure 8 was evaluated without consideration of non-crystalline phase. With only aging and without hydrothermal treatment, the product was of non-crystalline phase. By hydrothermal treatment for $48 \mathrm{~h}$, FAU zeolite was generated. The diffraction peak intensity was
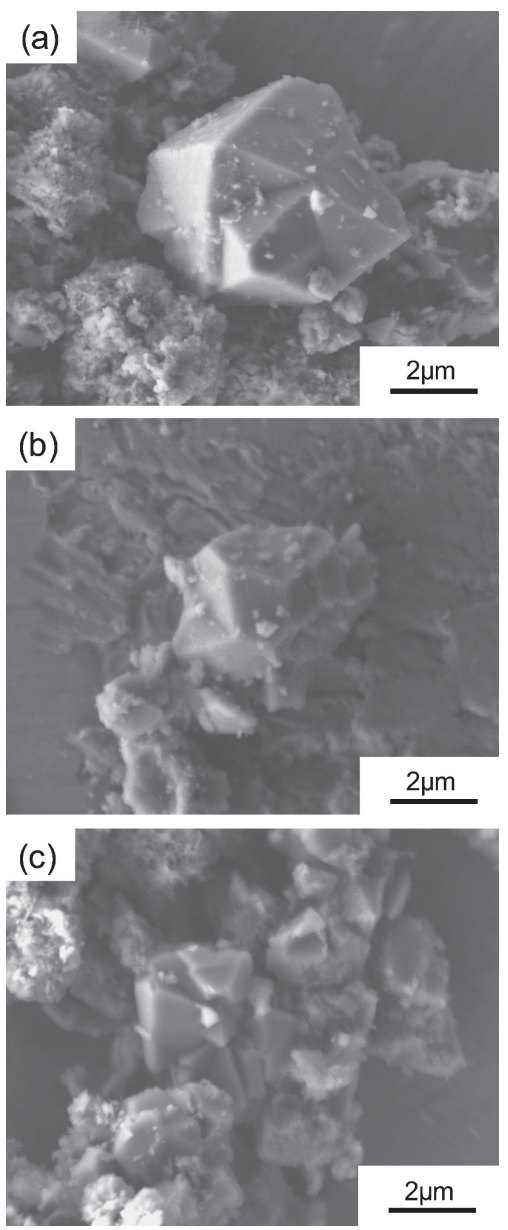

Fig. 6. SEM images of the products obtained by hydrothermal treatment at $348 \mathrm{~K}$ for $96 \mathrm{~h}$ with $2.0 \mathrm{~mol} / \mathrm{L} \mathrm{NaOH}$, after aging for (a) 48 , (b) 96 and (c) $240 \mathrm{~h}$. Si/Al ratio was 2.1 .

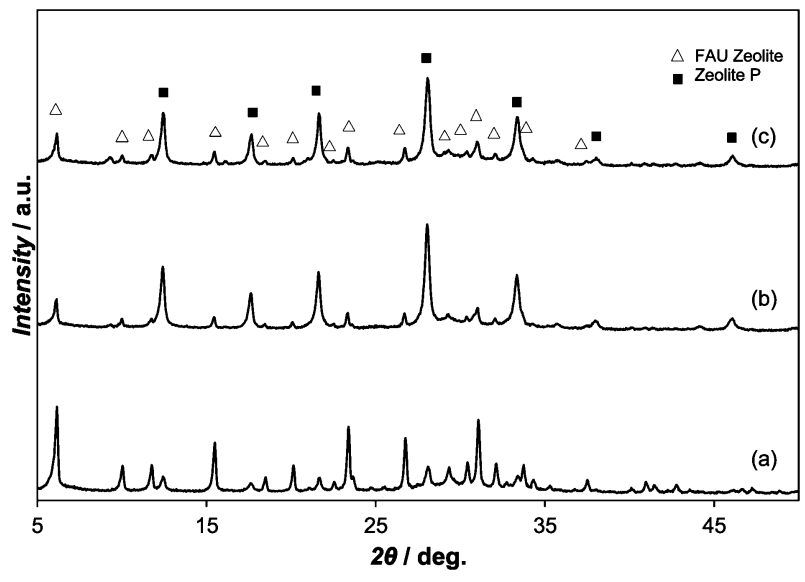

Fig. 7. XRD patterns of the products obtained by hydrothermal treatment at $348 \mathrm{~K}$ for $96 \mathrm{~h}$, after aged at (a)298, (b)313 and (c) $323 \mathrm{~K}$ for $96 \mathrm{~h}$, with $2.0 \mathrm{~mol} / \mathrm{L} \mathrm{NaOH}$, when $\mathrm{Si} / \mathrm{Al}$ ratio was 2.1 .

relatively weak; it was estimated that the production volume of FAU zeolite was small and a lot of non-crystalline phase remained. After hydrothermal treatment of $96 \mathrm{~h}$, zeolite $\mathrm{P}$ was generated in addition to FAU zeolite. This is because parts of FAU zeolite transformed into zeolite $\mathrm{P}$, which is a more stable 


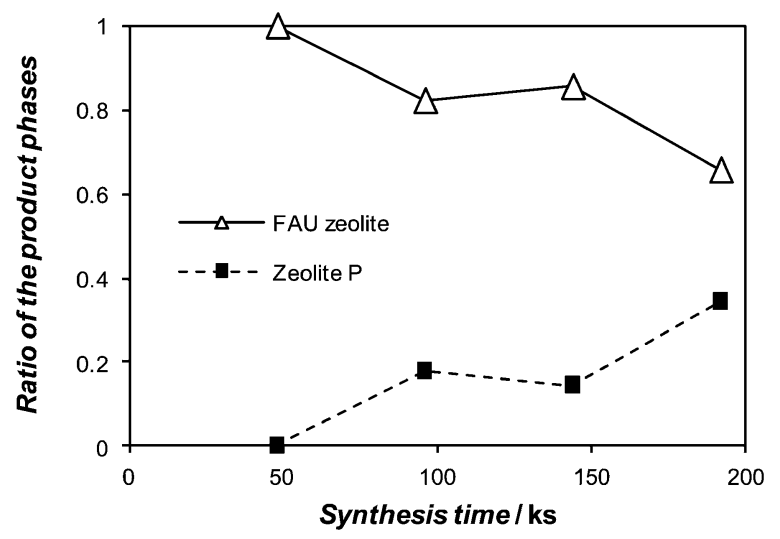

Fig. 8. Ratio of the product phases as a function of synthesis time when hydrothermally treated at $348 \mathrm{~K}$ after $96 \mathrm{~h}$ aging, with $2.0 \mathrm{~mol} / \mathrm{L} \mathrm{NaOH}$. $\mathrm{Si} / \mathrm{Al}$ ratio was 2.1 .

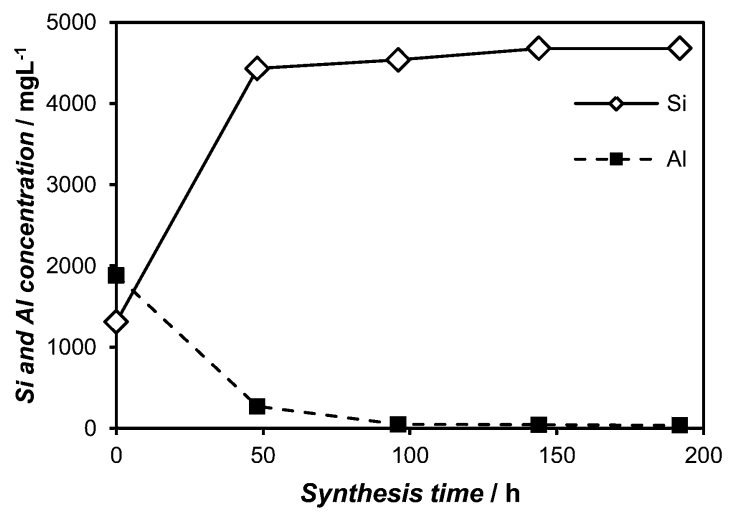

Fig. 9. $\mathrm{Si}$ and $\mathrm{Al}$ concentrations in the solution as functions of synthesis time when hydrothermally treated at $348 \mathrm{~K}$ after $96 \mathrm{~h}$ aging, with $2.0 \mathrm{~mol} / \mathrm{L} \mathrm{NaOH}$. Si/Al ratio was 2.1 .

phase than FAU zeolite, by hydrothermally treating for a long time period. This result agreed with previous reports. ${ }^{7)}$

Figure 9 shows $\mathrm{Si}$ and $\mathrm{Al}$ concentrations in the solution evaluated by ICP-AES analysis. Just after starting hydrothermal treatment, Si concentration in the solution increased significantly. This indicates that the elution of Si was accelerated by heating the solution. Meanwhile, Al concentration in the solution decreased substantially just after starting hydrothermal treatment. This is because $\mathrm{Al}$ in the solution was used for generating aluminosilicate species and zeolites. Si concentration in the solution increased with treatment time, despite parts of $\mathrm{Si}$ in the solution being consumed for the formation of non-crystalline aluminosilicate species and zeolites. This means that the elution of $\mathrm{Si}$ was accelerated dramatically by heating the solution. The produced aluminosilicate was also aged during hydrothermal treatment. As a result, the production of FAU zeolite increased slightly during hydrothermal treatment.

Figure 10 shows the ratio of each produced zeolite phase as a function of synthesis temperature. Figure 10 was evaluated without consideration of non-crystalline phase. When treatment temperature rose, the production of zeolite $\mathrm{P}$ increased and that of FAU zeolite decreased. These results indicate that at higher temperature zeolite $\mathrm{P}$, which is a more stable phase, was generated, therefore, to suppress the synthesis of zeolite P, the lowest possible temperature that can promote the FAU zeolite synthesis reaction is desired.

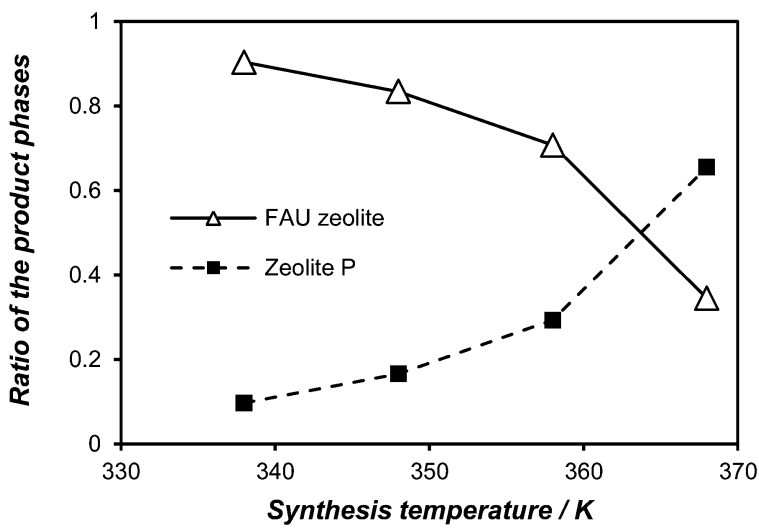

Fig. 10. Ratio of the product phases as a function of synthesis temperature when hydrothermally treated for $96 \mathrm{~h}$ with $2.0 \mathrm{~mol} / \mathrm{L} \mathrm{NaOH}$. $\mathrm{Si} / \mathrm{Al}$ ratio was 2.1 .

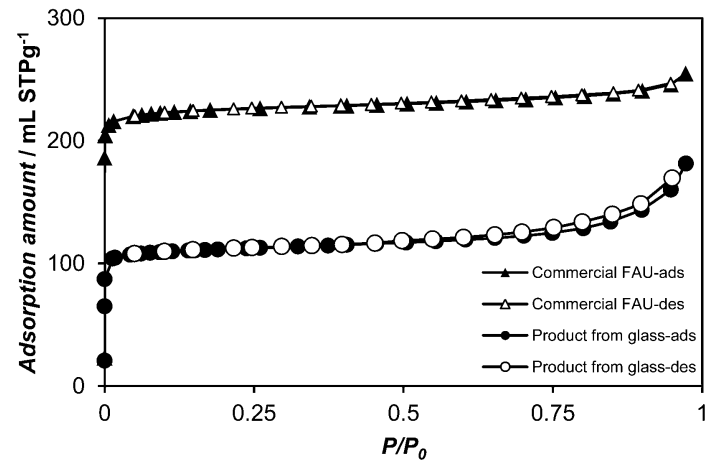

Fig. 11. Adsorption/desorption isotherms for the commercial FAU zeolite and the product obtained by hydrothermal treatment at $348 \mathrm{~K}$ for $96 \mathrm{~h}$, after aged at $298 \mathrm{~K}$ for $96 \mathrm{~h}$, with $2.0 \mathrm{~mol} / \mathrm{L} \mathrm{NaOH}$, when $\mathrm{Si} / \mathrm{Al}$ ratio was 2.1 .

Table 1. Specific Surface Areas of the commercial FAU zeolite and the product obtained by hydrothermal treatment at $348 \mathrm{~K}$ for $96 \mathrm{~h}$, after aged at $298 \mathrm{~K}$ for $96 \mathrm{~h}$

\begin{tabular}{lc}
\hline Samples & Specific surface area $/ \mathrm{m}^{2} \mathrm{~g}^{-1}$ \\
\hline Commercial FAU & 927 \\
The product from glass & 447 \\
\hline
\end{tabular}

\subsection{Microporus structure of synthesized FAU zeolite from aluminoborosilicate glass}

Figure 11 shows $\mathrm{N}_{2}$ adsorption/desorption measurements of the commercial FAU zeolite and the product obtained by aging at $298 \mathrm{~K}$ for $96 \mathrm{~h}$ followed by hydrothermal treatment at $348 \mathrm{~K}$ for $96 \mathrm{~h}$. The products showed the adsorption/desorption isotherms the typical Langmuir-type isotherms (type-I), which were derived from microporous structures of materials. The results of specific surface areas for the both samples are summarized in Table 1 . The product obtained after aging for $96 \mathrm{~h}$ from aluminoborosilicate glass had the specific surface area of $447 \mathrm{~m}^{2} / \mathrm{g}$. The commercial FAU zeolite had the specific surface area of $927 \mathrm{~m}^{2} / \mathrm{g}$. The specific surface area of the product was $48 \%$ of the commercial FAU zeolite. This value was in reasonably good agreement with the crystallinity derived from the XRD peak intensity of $43 \%$. Difference between the ratio of the specific surface area and the crystallinity from XRD was possibly due to coexistence of zeolite 
P. This result indicated that FAU zeolite obtained from aluminoborosilicate glass, which constituted about half of the product, had almost the same microporus structure with the pure FAU zeolite.

\section{Conclusions}

FAU zeolite was successfully synthesized by aging the solution before hydrothermal treatment, however zeolite $\mathrm{P}$ was also generated slightly. We clarified that it is necessary to select the appropriate $\mathrm{NaOH}$ concentration, aging time and synthesis conditions to obtain highly pure FAU zeolite because of the difficult solubility of aluminoborosilicate glass.

With diluted $\mathrm{NaOH}$ solution, aluminoborosilicate glass did not elute sufficiently, therefore zeolite A, which is low silica zeolite, was generated. With increasing aging time before hydrothermal treatment, the production of synthesized FAU zeolite increased. Aluminoborosilicate glass eluted gradually, and aluminosilicate species were generated. During the aging process, the precursor increased with aging time. Different from using pure reagent as a starting material, relatively long-term aging was necessary to generate FAU zeolite.

A high hydrothermal treatment temperature and long treatment time accelerated the elution of aluminoborosilicate glass, whereas stable phase zeolite $\mathrm{P}$ was generated. To suppress the synthesis of zeolite $\mathrm{P}$, the lowest possible temperature that can promote the FAU zeolite synthesis reaction is desired.

In this study, the framework structures of the products, such as the location of Al, Al-deficiency have not been clearly understood. These properties have relationship with the stability of zeolite materials. There are potential of future work about obtained products from aluminoborosilicate glass toward the practical use of catalysts, adsorbents and so.

In this study, FAU zeolite with the good microporus structure was successfully obtained. A longer aging period was necessary than using silica as a starting material. This result may cause cost rise. Meanwhile, the expectation to recycle waste glass from LCD-TV to a functional material, which costs to dispose now, will take economical advantage, as well as benefits to the environmental.

\section{References}

1) H. Koyama and R. Nakazawa, Ceram. Japan, 47, 81-85 (2012).

2) D. W. Breck, "Zeolite Molecular Sieves", Wiley, New York (1974).

3) M. Ogura, Y. Kawazu, H. Takahashi and T. Okubo, Chem. Mater., 15, 2661-2667 (2003).

4) D. M. Ginter, A. T. Bell and C. J. Radke, Zeolites, 12, 742-749 (1992).

5) D. W. Ginter, G. T. Went, A. T. Bell and C. J. Radke, Zeolites, 12, 733-741 (1992).

6) S. Khodabandeh and M. E. Davis, Microporous Mater., 12, 347-359 (1997).

7) M. Osada, I. Sasaki, M. Nishioka, M. Sadakata and T. Okubo, Microporous Mesoporous Mater, 23, 287-294 (1998).

8) Y. Kuwahara, T. Ohmichi, T. Kamegawa, I. Katayama and H. Yamashita, J. Mater. Sci., 43, 2407-2410 (2008).

9) Y. Kuwahara, T. Ohmichi, T. Kamegawa, K. Mori and H. Yamashita, J. Mater. Chem., 20, 5052-5062 (2010).

10) Y. Kuwahara, T. Ohmichi, T. Kamegawa, K. Mori and H. Yamashita, J. Mater. Chem., 19, 7263-7272 (2009).

11) T. Murakami, Y. Sugano, T. Narushima, Y. Iguchi and C. Ouchi, ISIJ Int., 51, 901-905 (2011).

12) E. Dempsey, G. H. Kuhl and D. H. Olson, J. Phys. Chem., 73, 387-390 (1969).

13) H. Kacirek and H. Lechert, J. Phys. Chem., 79, 1589-1593 (1975).

14) B. A. Williams, S. M. Babitz, J. T. Miller, R. Q. Snurr and H. H. Kung, Appl. Catal., A, 177, 161-175 (1999).

15) J. Ward, J. Catal., 9, 225-236 (1967).

16) J. B. Peri, J. Phys. Chem., 69, 231-239 (1965).

17) R. M. Barrer, Proc. Chem. Soc., 99-112 (1958).

18) S. Yoshida, N. Ogawa, K. Kamioka, S. Hirano and T. Mori, Adsorption, 5, 57-61 (1999).

19) M. Tsujiguchi, T. Kobashi, J. Kanbara, Y. Utsumi, N. Kakimori and A. Nakahira, J. Soc. Mater. Sci. Japan, 62, 357-361 (2013).

20) R. L. Snyder, Powder Diffraction, 7, 186-193 (1992).

21) N. Murayama, H. Yamamoto and J. Shibata, Int. J. Miner. Process., 64, 1-17 (2002).

22) H. J. Koroglu, A. Sarioglan, M. Tatlier, A. Erdem-Senatalar and O. T. Savasci, J. Cryst. Growth, 241, 481-488 (2002). 